mutism and other neurotic disorders; and he continues- "In the course of his investigations and experiments with calabar bean he noticed the beneficial action of the local application of this drug in some cases of acute glaucoma before the special therapeutic properties of this drug in glaucoma had been observed, so far as the writer of this notice is aware, by any other person. His explanation of the modus operandi of calabar bean in this disease was faulty, but the observation was well-founded and correct."

(To be concluded)

\title{
NOTES ON THREE CASES OF ACQUIRED ASTIGMATISM ASSOCIATED WITH MEIBOMIAN CYSTS BY
}

\author{
ARthur W. ORMOND, C.B.E., F.R.C.S., \\ LONDON.
}

Mrs. H., aet. 49.-Came complaining of loss of sight in L.E. On examination, I noticed the presence of a Meibomian cyst in the left upper lid.

Note by Mr. McGillivray, made three months earlier.

External appearance, normal. Pupils, normal. Ophthal., negative. No cyst of lids. R.V. $=6 / 5$ freely. L.V. $=6 / 5$ partly $\bar{c} .+0 \cdot 25$ D. cyl. V. $=6 / 5$. (Nothing unusual to record.) General health excellent.

30 September, 1919.-R.V. $=6 / 5 . \quad$ L.V. $=6 / 18$ incorrectly. On retinoscopic examination, a whorled shadow was noticed, with strong plus shadows. Vision of L.E. was improved to $6 / 6$ by $\frac{+2 \text { D. sph. }}{+5 \text { D. cyl. vert. }}$ The cyst having been successfully dealt with, the vision was found a day or two later to be $6 / 5$ without any glass, and the patient no longer complained of defective vision.

J. W., aet. 64.-Came complaining of gradual failure of sight in L.E. Was wearing R.E. +2 D. sph., L.E. +2.5 D. sph. ordered in New Zealand. Had a Meibomian cyst in the left upper lid.

14 September, 1920.-R.V. 6/9 $\bar{c}-0.5$ D. cyl. vert. $=6 / 5$. L.V.

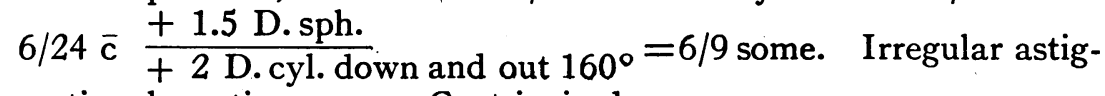
matism by retinoscopy. Cyst incised.

1 October, 1920.-R.V. $\bar{c}-0.5$ D. cyl. vert. $=6 / 5$. L.V. $\bar{c}+1.25$ D. cyl. down and out $=6 / 5$.

Patient remarked on the disappearance of his symptoms in the interval. 
E. C.S., aet. 55.-Complained of failure of sight in right eye. R.V. $6 / 24 \overline{\mathrm{c}} \frac{-1 \text { D.sph. }}{-1 \text { D.cyl. hor. }}=6 / 18$ not improved. L.V. 6/12 $\overline{\mathrm{c}}$ $\frac{-0.5 \text { D. sph. }}{-0.75 \text { D. cyl. hor. }}=6 / 6$ (R.V.in 1918 had 6/5 $\bar{c}-1$ D. sph.) Sight in right eye failed gradually. Cyst in right upper lid. Incised. Noticed the improvement in his vision the day following the incision of the cyst.

18 January, 1921.-R.V. $6 / 9 \mathrm{c} \frac{-0.5 \mathrm{D} . \mathrm{sph} .}{+1 \mathrm{D} . \mathrm{cyl} \text {. down }}$ and in $60^{\circ}=6 / 5$ slowly.

L.V. $\frac{\overrightarrow{\mathrm{c}}-0.5 \mathrm{D} . \mathrm{sph} .}{-0.75 \mathrm{D} \text { cyl hor }}=6 / 5$ most. J $1 \mathrm{c}+2.5$

D.sph.added.

These three cases appear to me to be of some interest, and, as far as I know (although probably the condition has been noticed before) I do not think it has been recorded, and the first case certainly found me unprepared for the dénouement.

All these cases had a Meibomian cyst in the upper lid, which showed some degree of chronicity, and the cysts were hard and protuberant. All three patients had become accustomed to the cyst and did not associate their failure of vision with its presence. All complained of a gradual failure of sight in the eye having the cyst, and all recovered normal vision after removal of the tumour. I should say that the ocular tension in all three cases was rather subnormal than normal, although I have no accurate tonometric measurements.

The amount of temporary astigmatism produced varied with the size of the tumour, the first case having by far the largest cyst. The second case seems to have increased the hypermetropia as well as the astigmatism. The retinoscopic shadows were broken up and whorled as in conical corneae in all three cases.

I have to thank Mr. McGillivray for his note regarding the first patient and Mr. Leslie Paton, who saw her after I did.

\section{SOME EXAMPLES OF IDIOSYNCRASY}

BY

\section{T.' HARRISON BUTLER \\ BIRMINGHAM}

THE effects of an idiosyncrasy may occasionally cause serious symptoms and may affect the reputation of the practitioner who is responsible for administering the remedy which has had an unusual effect. It seems wise, therefore, that cases of this type should be 